\title{
Renal Cysts as Strongest Association with Abdominal Aortic Aneurysm in Elderly
}

\author{
Toshiro Ito, MD, Ph.D, ${ }^{1}$ Nobuyoshi Kawaharada, MD, Ph.D, ${ }^{1}$ Yoshihiko Kurimoto, MD, Ph.D, ${ }^{2}$ \\ Atsushi Watanabe, MD, Ph.D, ${ }^{1}$ Kazutoshi Tachibana, MD,${ }^{1}$ Ryo Harada, MD,${ }^{1}$ Toshiyuki Maeda, MD, ${ }^{1}$ \\ Hitoki Hashiguchi, MD, ${ }^{1}$ Makoto Hashimoto, MD ${ }^{1}$ and Tetsuya Higami, MD, Ph.D ${ }^{1}$
}

Objective: The aim of this study is to investigate the positive association between the presence of renal cysts and AAA.

Patients and Methods: A retrospective chart review on the clinical data of 396 consecutive patients, who underwent CT scans for preoperative evaluation of thoracic and cardiovascular surgery in Sapporo Medical University from the period of January 2007 to December 2008, was conducted.

Results: When comparing patients with renal cysts $(n=164)$ to those without $(n=233)$, there was a statistically significant difference between the presence of renal cysts and male gender $(p=0.007)$, hypertension $(p=0.003)$, and AAA $(p<0.001)$ on univariate analysis. In addition, when comparing patients with AAA to those without, although COPD but not AAA was associated with renal cysts in less than 65 years old, the presence of renal cysts was the strongest association with AAA among patients belonging to the 65 to 74 years old group and over 75 years old group on multivariate analysis.

Conclusions: There is a statistically higher incidence of renal cysts in patients with AAA compared to patients without AAA in the group of elder cardiovascular patients. It is likely that AAA and renal cysts share a common pathogenesis.

Key words: abdominal aortic aneurysm, renal cysts, COPD

\section{INTRODUCTION}

A bdominal aortic aneurysm (AAA) is a common and potentially life-threatening vascular disease. Because of high mortality rate from the rupture of AAA, screening evaluation is advocated for high-risk subjects. The well known risk factors for AAA include advanced

${ }^{1}$ Department of Thoracic and Cardiovascular Surgery, Sapporo Medical University, School of Medicine, Hokkaido, Japan

${ }^{2}$ Department of Traumatology and Critical Care Medicine, Sapporo Medical University, School of Medicine, Hokkaido, Japan

Received: February 23, 2010 Accepted: June 2, 2010

Address for reprint requests to Toshiro Ito, MD, Ph.D: Department of Thoracic and Cardiovascular Surgery, Sapporo Medical University, School of Medicine, South-1 West-16, Chuo-ku, Hokkaido 060-8543, Japan

Tel:+81-11-611-2111 (ex:3312), Fax: +81-11-613-7318

E-mail address: t.ito@sapmed.ac.jp age, male gender, hypertension, atherosclerosis, COPD, and smoking. ${ }^{1,2)}$ Therefore, there are many potential candidates for the development of AAA.

When AAA was evaluated on computed tomography (CT) scanning, high frequency of renal cysts was encountered at the same time. If an association between the two exists, the presence of renal cysts may be a predictor for the development of AAA. The aim of this study is to investigate the positive association between the presence of renal cysts and AAA.

\section{Patients And Methods}

A retrospective chart review on the clinical data of 396 consecutive patients, who underwent CT scans for preoperative evaluation of thoracic and cardiovascular surgery in Sapporo Medical University from the period of January 2007 to December 2008, was conducted. 
Eight patients, who were diagnosed with chronic renal failure and were maintained on hemodialysis, were excluded. Renal cysts were detected by the presence of low density mass area on non-contrast $5 \mathrm{~mm}$-sliced CT images. The definitions of abdominal aortic aneurysm (AAA) and thoracic aortic aneurysm (TAA) were maximal diameters of the aortic aneurysm of $>40 \mathrm{~mm}$ and $>$ $50 \mathrm{~mm}$, respectively. The patient characteristics of age, gender, and the presence of hypertension, dyslipidemia, and diabetes mellitus (DM) were evaluated. Coronary artery disease (CAD) was assessed using dipyridamole thallium scintigraphy or coronary angiography. Chronic obstructive pulmonary disease (COPD) was defined as a ratio of forced expiratory volume in 1 second (FEV1) divided by forced vital capacity (FVC) of $<70 \%$. Two separate analyses were performed. First, patients with renal cysts were compared to patients without renal cysts in order to determine which cardiovascular diseases were associated with renal cysts. Second, patients with AAA were compared to patients without AAA in order to determine which variables were associated with AAA. Statistical analyses, including univariate and multivariate analyses, were performed by Fisher's exact test, MannWhitney test, and logistic regression analysis. Factors of value of $p<0.1$ in univariate analysis were performed by multivariate analysis in each group. Value of $p<0.05$ was considered statistically significant.

\section{RESULTS}

\section{Patients characteristics}

Patients characteristics of this study are listed in Table 1. The mean age was 68.3 years old, with male gender distribution of $66.9 \%$. Of the 396 patients, 259 (65.4\%) were diagnosed with hypertension, 101 (25.5\%) with dyslipidemia, 61 (15.4\%) with DM, and 91 (23.0\%) with COPD. The prevalence of renal cysts in all patients was $41.3 \%$. There were 124 patients (31.2\%) diagnosed with AAA.

\section{Association of AAA with renal cysts}

Patients with renal cysts $(n=164)$ were compared to patients without renal cysts $(n=233)$ in order to determine which variables or cardiovascular diseases were associated with renal cysts (Table 2). On univariate analysis, there was a statistically significant difference between the presence of renal cysts and male gender $(p=$ $0.007)$, hypertension $(p=0.003)$, and AAA $(p<0.001)$. Mitral valve regurgitation (MR) demonstrated a negative

\section{Table 1 Patients characteristics}

\begin{tabular}{lc}
\hline Number & 396 \\
Mean age (year) & $68.3 \pm 12.4$ \\
Male gender & $265(66.9 \%)$ \\
Hypertension & $259(65.4 \%)$ \\
Dyslipidemia & $101(25.5 \%)$ \\
DM & $61(15.4 \%)$ \\
COPD & $91(23.0 \%)$ \\
AAA & $124(31.2 \%)$ \\
CAD & $105(26.4 \%)$ \\
Aortic dissection & $81(20.4 \%)$ \\
ASO & $59(14.9 \%)$ \\
TAA & $57(14.4 \%)$ \\
AS & $32(8.1 \%)$ \\
MR & $25(6.3 \%)$ \\
AR & $20(5.0 \%)$ \\
MS & $10(2.5 \%)$ \\
Renal cysts & $164(41.3 \%)$ \\
Liver cysts & $68(17.1 \%)$ \\
\hline
\end{tabular}

DM: diabetes mellitus, COPD: chronic obstructive pulmonary disease, AAA: abdominal aortic aneurysm, CAD: coronary arterial disease, ASO: arteriosclerosis obliterans, TAA: thoracic aortic aneurysm, AS: aortic valve stenosis, MR: mirtal valve regurgitation, AR: aortic valve regurgitation, MS: mitral valve stenosis

association with renal cysts $(p=0.035)$. Furthermore, the mean age of patients with renal cysts was 70.0 years old and 66.7 years old for those without renal cysts. This finding indicated that advanced age significantly affected the prevalence of renal cysts.

\section{Renal Cysts as independent risk factor for AAA}

It is well known that advanced age is one of the significant risk factors for AAA, as well as renal cysts. Therefore, we divided all patients in three groups according to age, and then compared the patients with AAA to patients without AAA in order to determine which variables were associated with AAA. Table 3 shows the results of univariate and multivariate analysis in the less than 65 years old group. Only COPD was associated with AAA and odds ratio was estimated at 6.37 by multivariate analysis. Among the patients belonging to the 65 to 74 years old group, gender (male), COPD, and the presence of renal cysts were associated with AAA on univariate analysis (Table 4) and the presence of renal cysts was the strongest independent association with AAA on multivariate analysis. For over 75 years old group, gender 
Table 2 Univariate analysis of renal cysts and observed patients' cardiovascular disease

\begin{tabular}{lccc}
\hline & Patients with renal cysts & Patients without renal cysts & $p$ \\
\hline Number (\%) & $164(41.3 \%)$ & $233(58.7 \%)$ & - \\
Mean age (year) & $70.0 \pm 10.9$ & $66.7 \pm 13.7$ & 0.020 \\
Gender (male) & $76.2 \%$ & $65.7 \%$ & 0.007 \\
Hypertension & $74.8 \%$ & $60.2 \%$ & 0.003 \\
Dyslipidemia & $27.9 \%$ & $26.4 \%$ & 0.813 \\
DM & $11.4 \%$ & $18.1 \%$ & 0.085 \\
COPD & $26.6 \%$ & $25.1 \%$ & 0.793 \\
TAA & $18.6 \%$ & $11.6 \%$ & 0.059 \\
AAA & $43.5 \%$ & $23.3 \%$ & $<0.001$ \\
Aortic dissection & $24.8 \%$ & $17.6 \%$ & 0.099 \\
CAD & $29.0 \%$ & $31.3 \%$ & 0.719 \\
AS & $5.6 \%$ & $10.3 \%$ & 0.138 \\
AR & $5.0 \%$ & $5.2 \%$ & 1.000 \\
MS & $1.9 \%$ & $3.0 \%$ & 0.536 \\
MR & $3.1 \%$ & $8.6 \%$ & 0.035 \\
\hline
\end{tabular}

Table 3 Univariate and multivariate analysis of AAA in less than 65 years old

\begin{tabular}{lccccc}
\hline & \multicolumn{3}{c}{ Univariate analysis } & \multicolumn{2}{c}{ Multivariate analysis } \\
& $\begin{array}{c}\text { Patients } \\
\text { with AAA }\end{array}$ & $\begin{array}{c}\text { Patients } \\
\text { without AAA }\end{array}$ & $p$ & Odds ratio & $\begin{array}{c}95 \% \text { confidence } \\
\text { interval }\end{array}$ \\
\hline Number (\%) & $16(13.6 \%)$ & $102(86.4 \%)$ & - & - & - \\
Gender (male) & $87.5 \%$ & $71.6 \%$ & 0.232 & - & - \\
Hypertension & $68.8 \%$ & $54.9 \%$ & 0.417 & - & - \\
Dyslipidemia & $31.2 \%$ & $19.6 \%$ & 0.326 & - & - \\
DM & $0 \%$ & $11.8 \%$ & 0.366 & 6.37 & - \\
COPD & $55.6 \%$ & $16.4 \%$ & 0.018 & - & - \\
Renal cysts & $37.5 \%$ & $29.4 \%$ & 0.564 & - & - \\
Liver cysts & $12.5 \%$ & $14.7 \%$ & 1.000 & - & - \\
\hline
\end{tabular}

Table 4 Univariate and multivariate analysis of AAA between 65 to 74 years old

\begin{tabular}{|c|c|c|c|c|c|c|}
\hline & \multicolumn{3}{|c|}{ Univariate analysis } & \multicolumn{3}{|c|}{ Multivariate analysis } \\
\hline & $\begin{array}{c}\text { Patients } \\
\text { with AAA }\end{array}$ & $\begin{array}{c}\text { Patients } \\
\text { without AAA }\end{array}$ & $p$ & Odds ratio & $\begin{array}{c}95 \% \text { confidence } \\
\text { interval }\end{array}$ & $p$ \\
\hline Number (\%) & $56(38.9 \%)$ & $88(51.1 \%)$ & - & - & - & - \\
\hline Gender (male) & $80.4 \%$ & $63.6 \%$ & 0.040 & 1.09 & $0.41-2.94$ & 0.858 \\
\hline Hypertension & $67.3 \%$ & $68.2 \%$ & 1.000 & - & - & - \\
\hline Dyslipidemia & $37.0 \%$ & $29.5 \%$ & 0.263 & - & - & - \\
\hline $\mathrm{DM}$ & $14.8 \%$ & $26.1 \%$ & 0.144 & - & - & - \\
\hline COPD & $40.5 \%$ & $23.6 \%$ & 0.082 & 2.41 & $0.94-6.18$ & 0.068 \\
\hline Renal cysts & $62.5 \%$ & $35.6 \%$ & 0.002 & 4.15 & $1.72-10.03$ & 0.002 \\
\hline Liver cysts & $17.9 \%$ & $14.8 \%$ & 0.648 & - & - & - \\
\hline
\end{tabular}


Table 5 Univariate and multivariate analysis of AAA over 75 years old

\begin{tabular}{lcccccc}
\hline & \multicolumn{3}{c}{ Univariate analysis } & \multicolumn{3}{c}{ Multivariate analysis } \\
\hline & $\begin{array}{c}\text { Patients } \\
\text { with AAA }\end{array}$ & $\begin{array}{c}\text { Patients } \\
\text { without AAA }\end{array}$ & $p$ & Odds ratio & $\begin{array}{c}95 \% \text { confidence } \\
\text { interval }\end{array}$ & $p$ \\
\hline Number (\%) & $52(39.1 \%)$ & $81(60.9 \%)$ & - & - & - & - \\
Gender (male) & $80.8 \%$ & $60.5 \%$ & 0.021 & 2.62 & $0.75-9.19$ & 0.132 \\
Hypertension & $60.8 \%$ & $81.0 \%$ & 0.015 & 0.43 & $0.15-1.19$ & 0.103 \\
Dyslipidemia & $14.6 \%$ & $29.1 \%$ & 0.084 & 0.74 & $0.24-2.26$ & 0.593 \\
DM & $14.8 \%$ & $26.1 \%$ & 0.065 & 0.40 & $0.93-1.75$ & 0.224 \\
COPD & $62.2 \%$ & $41.1 \%$ & 0.058 & 2.33 & $0.90-6.02$ & 0.082 \\
Renal cysts & $55.8 \%$ & $37.5 \%$ & 0.049 & 3.00 & $1.16-7.73$ & 0.023 \\
Liver cysts & $26.9 \%$ & $16.3 \%$ & 0.185 & - & - & - \\
\hline
\end{tabular}

(male) and the presence of renal cysts were positively associated with AAA. On the other hand, hypertension was negatively associated with AAA (Table 5). On multivariate analysis, the presence of renal cysts was revealed as the only independent positive association with AAA.

\section{DisCUSSION}

In the current study, AAA is a statistically positive risk factor associated with renal cysts among the cardiovascular diseases. In addition, in comparison of the patients with AAA to those without, the presence of renal cysts shows the strongest independent association with AAA among the patients belonging to the 65 to 74 years old group and over 75 years old group.

Yaghoubian et al. first reported that patients with AAA have a significantly increased incidence of renal cysts on CT scan compared to patients without AAA. ${ }^{3)}$ We also have empirically observed that patients with AAA seem to have a high prevalence of renal cysts. However, the risk factors for renal cysts, including advanced age, ${ }^{4-6)}$ male gender, ${ }^{7,8)}$ renal dysfunction, ${ }^{9)}$ and hypertension, ${ }^{10)}$ have been considered as atherosclerotic risk factors; wherein, in the comparison between patients with AAA to healthy people, the presence of arteriosclerosis possibly affected the results of analysis. Therefore, patients with cardiovascular diseases were subjected in this study. Although thoracic aortic aneurysm, coronary arterial disease, and atherosclerotic obstructive disease are representatives of atherosclerotic diseases, AAA was only a statistical association with the presence of renal cysts on univariate analysis. These results suggested that this association can be the result of a commonality in the pathogenesis of AAA and renal cysts.
In general, the pathogenesis of AAA is multifactorial, ${ }^{11)}$ in which, atherosclerosis, infection, and inflammation increased protease activity within the arterial wall. One of the important features of AAA is inflammation with the presence of a mononuclear inflammatory cell infiltrate in the aneurysmal tissue. ${ }^{12,13)}$ The inflammatory cell infiltrate is most likely the source of activated immune cells, as well as proteolytic enzymes, including the matrix metalloproteinases (MMPs). MMP-9 was reported to be expressed in the wall of $\mathrm{AAA}^{14)}$ and circulating levels of MMP-9 appeared to be raised in aneurysm diseases. ${ }^{15)}$ Genetically-engineered mice lacking the MMP-9 gene are resistant to AAA formation in this elastase infusion model supporting a role for MMPs in the development of AAA. ${ }^{16)}$

Renal cysts are the most common renal masses. Incidence increases with age and is reported to be $24 \%$ to $27 \%$ in CT studies in patients older than 50 years. ${ }^{17,18)}$ The mechanism behind the formation of simple renal cysts is not fully known. The most widely accepted theory maintains that elasticity decreases in the nephron basal membrane with advanced age. Parallel to previous reports, our study shows a positive association between renal cysts and advanced age, male gender, and hypertension on univariate analysis. It is also interesting to note that smoking is reported to be a risk factor for the occurrence of simple renal cysts. $\left.{ }^{6}\right)$ Although the risk factors for renal cysts are closely similar to those of AAA, few studies to date have investigated a commonality in the pathogenesis of AAA and renal cysts. Harada et al. reported that MMP-2 and -9 were detected in the cystic fluids of renal cyst. ${ }^{19)}$ Other report showed that the synthetic metalloproteinase inhibitor, batimastat, caused a reduction on the number of cysts in polycystic kidney of the rat. ${ }^{20)}$ These results 
suspected that MMPs played a role in the development of renal cysts. Although it is uncertain that these findings are specific for renal cysts only, to our knowledge, correlation between MMPs and liver cysts, wherein, no association with AAA is noted in our study, has not been reported.

Rarely, renal masses are associated with autosomal dominant polycystic kidney disease (ADPKD). ADPKD is genetically heterogeneous. Thus, two genes, $P K D I$ and PKD2 mutation, are implicated in its development. It occurs in 1 of 400-1,000 individuals and is characterized by renal and extrarenal disorders. Patients with ADPKD are reported to have increased incidence of intracranial aneurysm, ${ }^{21)}$ coronary aneurysm, ${ }^{22)}$ renal artery aneurysm, and splenic artery aneurysm, ${ }^{23)}$ Coexistence of AAA has been also reported in some ADPKD patients. ${ }^{24,25)}$ Kato et al. have reported that the incidence of AAA is $7.1 \%$ in ADPKD patients. ${ }^{25)}$ Other studies reported that aneurysmal development in ADPKD was caused by weakening of the vessel walls. Since polycystin 1 and polycystin 2 are both expressed in vascular smooth muscle cells, interactions of these proteins with a single pathway might have a role in the pathogenesis of aneurysm in ADPKD. Although 8 patients, who were diagnosed with chronic renal failure and were maintained on hemodialysis, were excluded in our study, rigid distinction between simple renal cysts and ADPKD was not performed. Thereafter, different pathogenesis of AAA for patients with renal cysts may be included in our study.

The current study signifies that the presence of renal cysts is not a risk factor for AAA in patients less than 65 years old. Although, among 65 to 74 years old and over 75 years old, renal cysts present with the strongest association with AAA, the association does not function as a predictor for the development of AAA. Instead, it is interesting to note that COPD is the only risk factor for AAA in less than 65 years old. COPD is also known to be the risk factor for development of AAA. Previous studies reported that MMPs were critically involved in the pathogenesis of COPD. It is likely that AAA, renal cysts, and COPD share the same pathogenesis, and COPD occurs in younger age than AAA and renal cysts. To our knowledge, no study on the association between COPD and renal cysts exists. Further studies are needed to investigate the coexistence of pathogenesis for AAA renal cysts and COPD.

\section{REFERENCES}

1) Forsdahl SH, Singh K, Solberg S, Jacobsen BK. Risk factor for abdominal aortic aneurysms. A 7-year prospective study: the Troms study, 1994-2001. Circulation 2009; 119: 2202-8.

2) Buckley C, Wyble CW, Borhani M, Ennis TL, Kobayashi DK, et al. Accelerated Enlargement of experimental abdominal aortic aneurysms in a mouse model of chronic cigarette smoke exposure. J Am Coll Surg 2004; 199: 896-903.

3) Yaghoubian A, de Virgilio C, White RA, Sarkisyan G. Increased incidence of renal cysts in patients with abdominal aortic aneurysm: a common pathogenesis? Ann Vasc Surg 2006; 20: 787-91.

4) Chin HJ, Ro H, Lee HJ, Na KY, Chae DW. The clinical significances of simple renal cyst: is it related to hypertension or renal dysfunction? Kidney International 2006; 70: 1468-73.

5) Mosharafa AA. Prevalence of renal cysts in a Middle Eastern population: an evaluation of characteristics and risk factors. BJU Int 2008; 101: 736-8.

6) Chang CC, Kuo JY, Chan WL, Chen KK, Chang LS. Prevalence and clinical characteristics of simple renal cyst. J Chin Med Assoc 2007; 70: 486-91.

7) Carrim ZI, Murchison JT. The prevalence of simple renal and hepatic cysts detected by spiral computed tomography. Clin Radiol 2003; 58: 626-9.

8) Terada N, Ichioka K, Matsuta Y, Okubo K, Yoshimura $\mathrm{K}$, et al. The natural history of simple renal cysts. J Urol 2002; 167: 21-3.

9) Al-Said J, Brumback MA, Moghazi S, Baumgarten DA, O'Neill WC. Reduced renal function in patients with simple renal cysts. Kidney Int 2004; 65: 2303-8.

10) Pedersen JF, Emamian SA, Nielsen MB. Significant association between simple renal cysts and arterial blood pressure. Br J Urol 1997; 79: 688-92.

11) Macsweeney STR, Powell JT, Greenhalgh RM. Pathogenesis of abdominal aortic aneurysm. Br J Sug 1994; 81: 935-41.

12) Kock AE, Haines GK, Rizzo RJ, Radosevich JA, Pope $\mathrm{RM}$, et al. Human abdominal aortic aneurysm. Immunophenotypic analysis suggesting an innume-mediated response. Am J Pathol 1990; 137: 1199-213.

13) Brophy CM, Reilly JM, Smith GJ, Tilson MD. The role of inflammation in nonspecific abdominal aortic aneurysm disease. Ann Vasc Surg 1991; 5: 229-33.

14) Sakalihasan N, Delvenne P, Nusgens BV, Limet $R$, Lapiere CM. activated forms of MMP2 and MMP9 in abdominal aortic aneurysms. J Vasc Surg 1996; 24: 127-33.

15) McMillan WD, Pearce WH. Increased plasma levels of matrix metalloproteinase- 9 are associated with abdominal aortic aneurysms. J Vasc Surg 1999; 29: 122-7.

16) Pyo R, Lee JK, Shipley JM, Curci JA, Mao D, et al. Targeted gene disruption of matrix metalloprotei- 
nase-9 (gelatinage B) suppresses development of experimental abdominal aortic aneurysm. J Clin Invest 2000; 105: 1641-9.

17) Laucks SP Jr, McLachlan MS. Aging and simple cysts of the kidney. Br J Radiol 1981; 54: 12-4.

18) Tada S, Yamagishi J, Kobayashi H, Hata Y, Kobari T. The incidence of simple renal cyst by computed tomography. Clin Radiol 1983; 34: 437-9.

19) Harada H, Furuya M, Ishikura H, Shindo J, Koyanagi T, et al. Expression of matrix metalloproteinase in the fluids of renal cystic lesions. J Urol 2002; 168: 19-22.

20) Obermüller N, Morente N, Kränzlin B, Gretz N, Witzgall R. A possible role for metalloproteinases in renal cyst development. Am J Physiol Renal Physiol 2001; 280: F540-50.

21) Chapman AB, Rubinstein D, Hughes R, Stears JC, Earnest MP, et al. Intracranial aneurysms in autosomal dominant polycystic kidney disease. N Engl J Med 1992; 327: 916-20.

22) Hadimeri H, Lamm C, Nyberg G. coronary aneurysms in patients with autosomal dominant polycystic kidney disease. J Am Soc Nephrol 1998; 9: 837-41.

23) Kanagasundaram NS, Perry EP, Turney JH. Aneurysm of the splenic artery in a patient with autosomal dominant polycystic kidney disease. Nephrol Dial Transplant 1999; 14: 183-4.

24) Torra R, Nicolau C, Badenas C, Bru C, Perez L, et al. abdominal aortic aneurysms and autosomal dominant polycystic kidney disease. J Am Soc Nephrol 1996; 7: 2483-6.

25) Kato A, Takita T, Furuhashi M, Maruyama Y, Hishida A. abdominal aortic aneurysms in hemodialysis patients with autosomal dominant polycystic kidney disease. Nephron 2001; 88: 185-6. 